\title{
Distributed Multi-Sensor Real-Time Building Environmental Parameters Monitoring System with Remote Data Access
}

\author{
Ivars Beinarts (Researcher, Riga Technical University), \\ Uldis Grunde (Researcher, Institute of Electronics and Computer Science), \\ Andris Jakovics (Associate Professor, University of Latvia)
}

\begin{abstract}
In this paper the advanced monitoring system of multiple environmental parameters is presented. The purpose of the system is a long-term estimation of energy efficiency and sustainability for the research test stands which are made of different building materials. Construction of test stands, and placement of main sensors are presented in the first chapter. The structure of data acquisition system includes a real-time interface with sensors and a data logger that allows to acquire and log data from all sensors with fixed rate. The data logging system provides a remote access to the processing of the acquired data and carries out periodical saving at a remote FTP server using an Internet connection. The system architecture and the usage of sensors are explained in the second chapter. In the third chapter implementation of the system, different interfaces of sensors and energy measuring devices are discussed and several examples of data logger program are presented. Each data logger is reading data from analog and digital channels. Measurements can be displayed directly on a screen using WEB access or using data from FTP server. Measurements and acquired data graphical results are presented in the fourth chapter in the selected diagrams. The benefits of the developed system are presented in the conclusion.
\end{abstract}

Keywords - Data acquisition; Energy efficiency; Remote monitoring.

\section{INTRODUCTION}

The data acquisition system (DAS) is an essential part of any monitoring and/or control system. Variety of DAS used in different applications is presented in [3], [4], [9], [10]. Their implementation covers a wide range of applications including medicine, weather, renewable energy, transport and buildings. As a rule they are distributed with web-based remote data access. The implementation of web-based data acquisition systems (WDAS) is representing an advanced technique providing the seamless interface from sensors to the end-user. Usage of distributed embedded web-servers gives the effective tool for the researchers to run experiments remotely and to share their results [5], [7], [11]. The proposed architectures of WDAS are different. However they possess certain common features that allow implementation, monitoring, logging, and analysis of experiments and their data without the presence of the researcher.

These features are important for the experiments that are connected with the energy efficiency monitoring, particularly with energy efficiency experiments of the test stands discussed further. The five test stands involved in the energy efficiency experiments [12] have been built using different local materials based on composite structures and renewable resources.

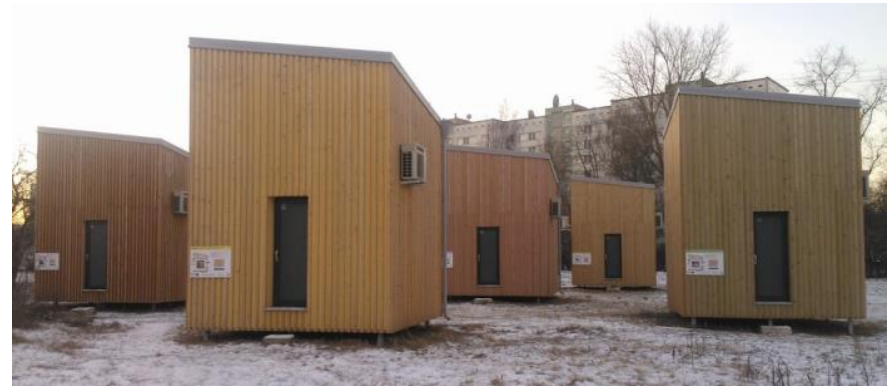

Fig. 1. Disposition of test stands.

They are named after the major materials used in the construction: the logs, the plywood, the ceramic bricks, the aerated concrete and the experimental ceramic bricks. All stands have the same stone wool insulation. Accordingly the names of the test stands are LOG, PLY, CER, AER and EXP. All of test stands shown in Fig. 1 have the same appearance, size, and orientation in space.

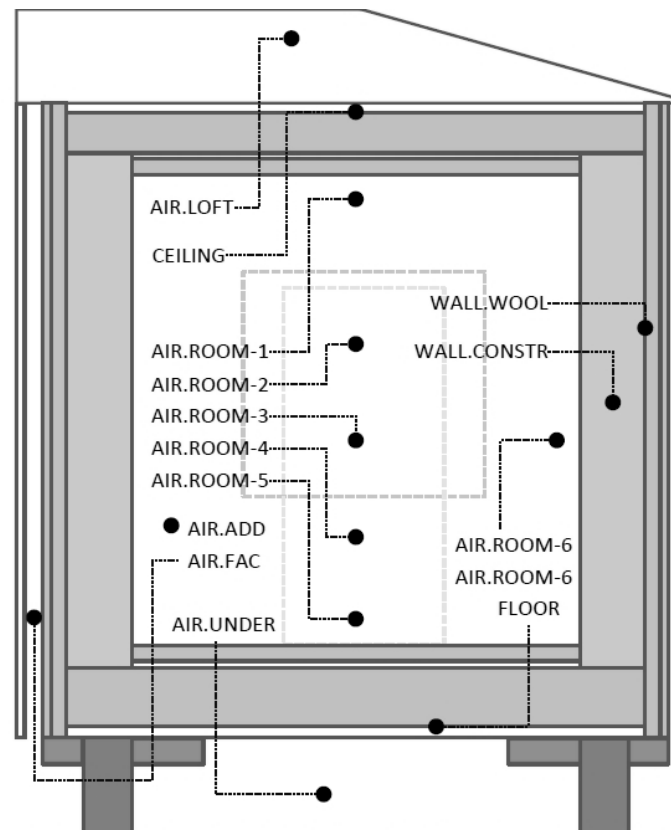

Fig. 2. Locations of $\mathrm{T} / \mathrm{H}$ sensors in a test stand. 
The sensors are located inside and outside the test stands, as well as built within the building constructions to measure thermal characteristics of the different building constructions and materials. All test stands have identical sets of sensors that are located in the same way. In total there are about 40 parameters measured by sensors in each test stand. The sensors include some temperature and humidity $(\mathrm{T} / \mathrm{H})$ sensors, with the location shown in Fig. 2, air flow velocity sensors, a solar radiation sensor, an electric energy meter, a differential air pressure sensor, a heat flux sensor, and a barometric pressure sensor. Each test stand is equipped with a heating, ventilation and air condition system (HVAC) with a control unit and a data logger. The data logger is collecting data from all sensors, including the data from the energy meters. To collect meteorological data, a weather station [19] is installed on the top of a test stand with the data logger installed inside the test stand.

\section{ARCHITECTURE OF THE SYSTEM}

The selected architecture of the system is developed to satisfy the user's requirements and provide all necessary services for the energy efficiency experiments. The above mentioned architectures of WDAS have been used in different applications not connected with energy efficiency experiments. Their architectural characteristics were chosen in order to meet the requirements of their application, and to satisfy their needs. However the characteristics can be split in two parts, one-characterizing WDAS general features, another - application specific features.

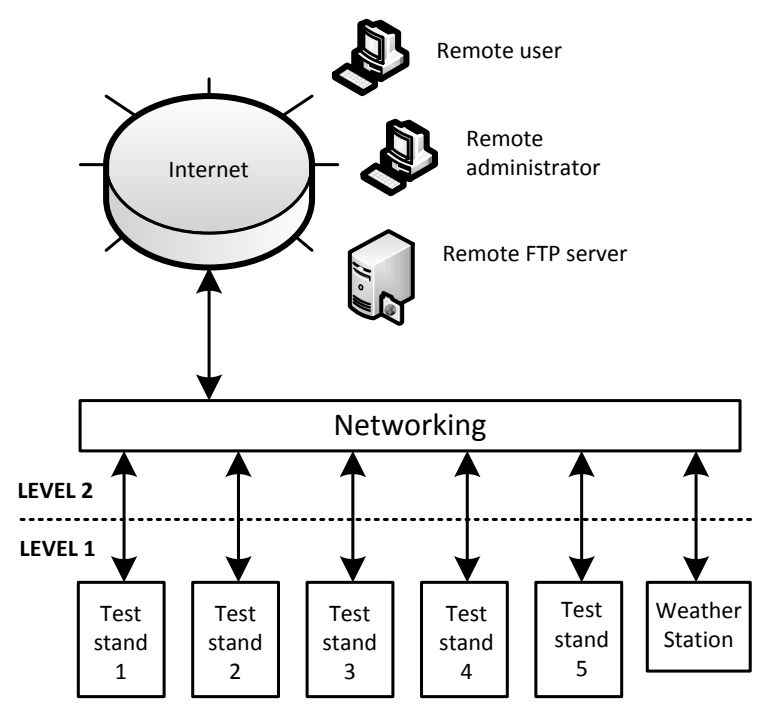

Fig. 3. WDAS structure.

WDAS designed for the energy efficiency monitoring should be unattended, distributed, modular and scalable, providing remote access to the data and to the software. These features allow to perform experiments that are connected with the energy efficiency without the presence of the researcher on-site. In addition, the proposed architecture of WDAS [1] should provide the real-time interface with the sensors, acquire and log data from all sensors with fixed rate, and send logged data using File Transfer Protocol (FTP) server.

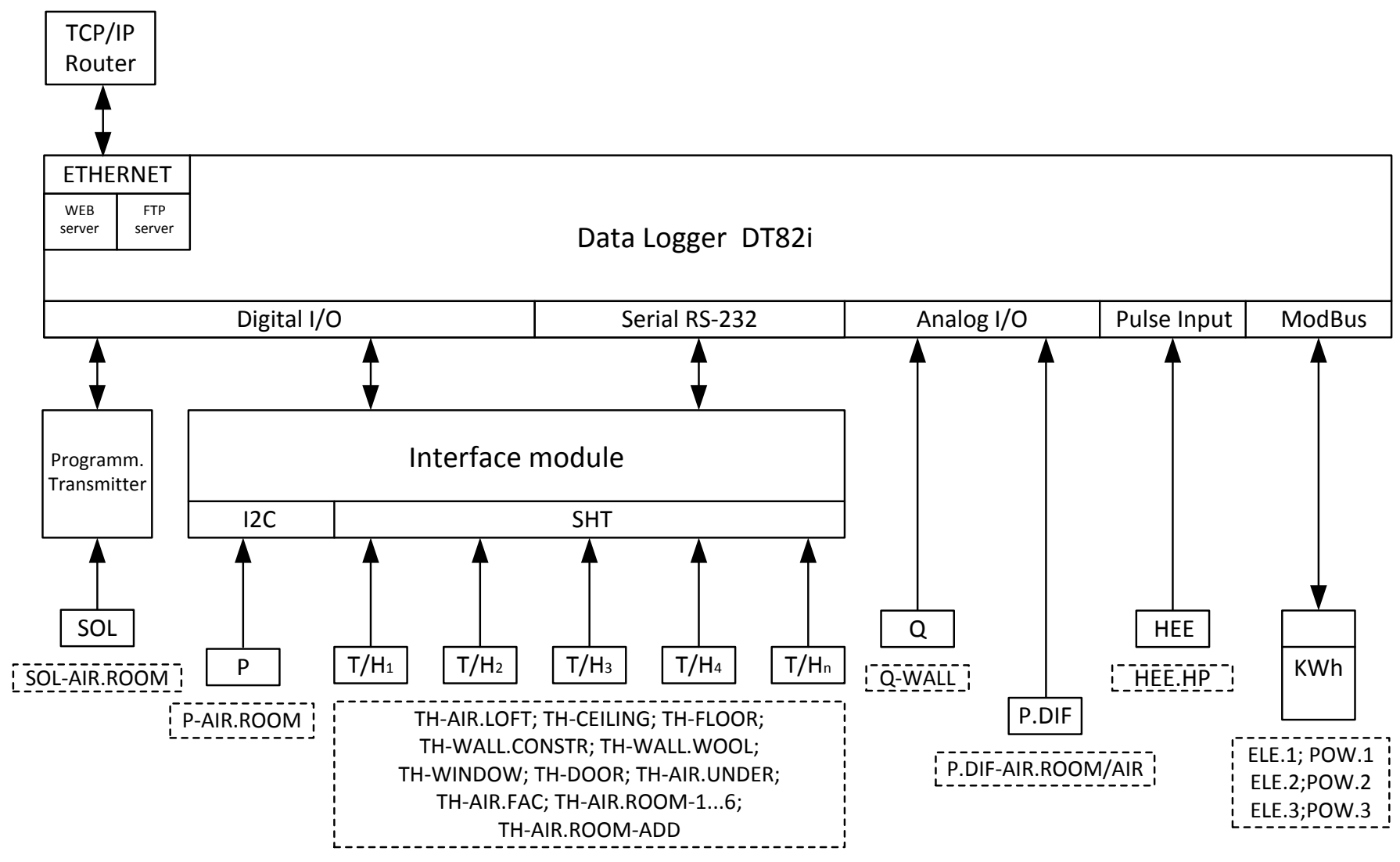

Fig. 4. WDAS structure of a test stand. 
A selected system architecture is shown in Fig. 3. It is presented with a two-level structure. The data acquisition equipment and sensors located in the test stands, as well as the weather station, is representing the first level. The second level is the networking equipment to the Internet. Both levels are connected via Ethernet.

The list of sensors used in DAS and their placement is shown in Table I.

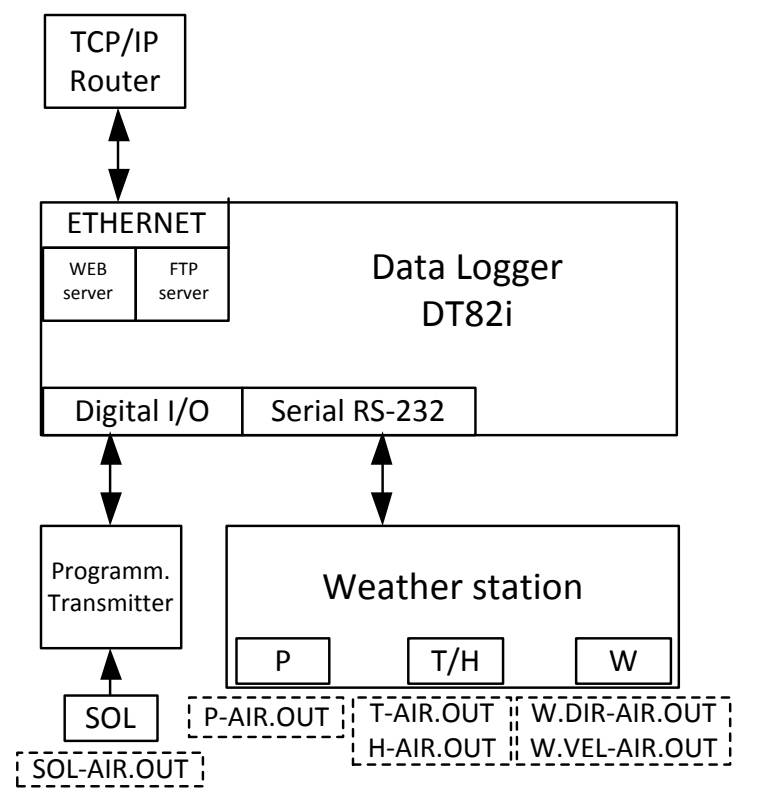

Fig. 5. Weather station WDAS structure.

TABLE I

DESCRIPTION OF DAS SENSORS LEGEND

\begin{tabular}{|c|l|}
\hline LEGEND & \multicolumn{1}{|c|}{ Parameter, Sensor Mount Place } \\
\hline ELE 1, 2, 3 & Electric Active Energy by lines L1, L2, L3 \\
\hline POW 1, 2, 3 & Electric Active Power by lines L1, L2, L3 \\
\hline HEE.HP & Heat Energy of Heat Pump \\
\hline TH-AIR.LOFT & Temp./Humidity Sensor (T/H) On Loft \\
\hline TH-CEILING & T/H On Ceiling Behind Isolation \\
\hline TH-FLOOR & T/H On Floor Behind Isolation \\
\hline TH-WALL.CONSTR & T/H In Center of Wall Construction \\
\hline TH-WALL.WOOL & T/H In Wall Before Isolation \\
\hline TH-WINDOW & T/H Near Window Opening \\
\hline TH-DOOR & T/H Near Door Opening \\
\hline TH-AIR.UNDER & T/H Under Test Stand \\
\hline TH-AIR.ROOM-1 & T/H On Center of Room 0.1 m From Ceiling \\
\hline TH-AIR.ROOM-2 & T/H On Center of Room. $H=1.7$ M \\
\hline TH-AIR.ROOM-3 & T/H On Center of Room. $H=1.1 \mathrm{M}$ \\
\hline TH-AIR.ROOM-4 & T/H On Center of Room. $H=0.6 \mathrm{M}$ \\
\hline TH-AIR.ROOM-5 & T/H On Center of Room. $H=0.1 \mathrm{M}$ \\
\hline TH-AIR.ROOM-6 & T/H 0.1 M from Outer Wall. $H=1.1 \mathrm{M}$ \\
\hline Q-WALL & Heat Flux Density on Surface of Outer Wall \\
\hline V-AIR.ROOM-1...N & Air Flow in Room \\
\hline P-AIR.ROOM & Air Pressure in Room \\
\hline P.DIF-AIR.ROOM & Air Pressure Difference in/out Of Room \\
\hline SOL-AIR.ROOM & Solar Radiation. In Center of Window \\
\hline W.DIR-AIR.OUT & Outdoor Wind Direction (Weather station) \\
\hline W.VEL-AIR.OUT & Outdoor Wind Velocity (Weather station) \\
\hline P-AIR.OUT & Outdoor Barometric Pressure (Weather station) \\
\hline H-AIR.OUT & Outdoor Air Humidity (Weather station) \\
\hline T-AIR.OUT & Outdoor Air Temperature (Weather station) \\
\hline SOL-AIR.OUT & Outdoor Solar Radiation (Weather station) \\
\hline
\end{tabular}

The second level includes several network switches, routers, and the wireless router providing access to the Internet. The structure of the first level components except the weather station is shown in Fig. 4. It includes three major parts: sensors, an interface module [2], and the data logger with built-in WEB and FTP servers. The structure of the first level components of weather station WDAS includes two major parts: weather station module with built-in sensors, and the data logger with WEB and FTP servers (Fig. 5).

The interface module is connected to the digital smart sensors that include temperature, humidity, and pressure sensors. Others, analog sensors, are connected directly to the data logger. During the selection of the connection type for sensors, wired and wireless options have been considered. The installation of sensors with wireless connection is fast and easy. It provides fast change of sensors and their location in the room. The usage of wired sensors does not require autonomous power supply for each sensor. Wired connections are not affected by the RF interferences, as well as the sensors themselves do not interfere with each other and other systems.

The wired sensor connection was preferred for WDAS, because it is more robust and more interference-resistant, and more available than wireless.

\section{IMPLEMENTATION OF THE SYSTEM}

The data logger DataTaker 82i was selected due to its basic characteristics [13] that conform the most to the needs of the users. It is a low power consumption data logger. It has embedded WEB and FTP servers. WEB access is providing real-time user's access to the data of each test stand. The WEB interface allows users to configure the data logger, to access the logged data, and to research current measurements as mimics or in a list using the web browser. FTP access makes it possible to access the data that are logged in the data logger. FTP service provides data transfer to the office over the internet without the need for polling or specific host software. According to the present settings, all loggers' data are sent once a day. All measurements obtained from all five test stands and the weather station are saved on FTP server. The FTP data are available for all users connected to the network. The screenshot of FTP data is shown in Fig. 6.

The data logger has enough analog inputs for analog sensors, pulse input for heat energy meter and two serial channels. One of the serial channels is used for Modbus connection, another, for the connection for all digital sensors through the interface module.

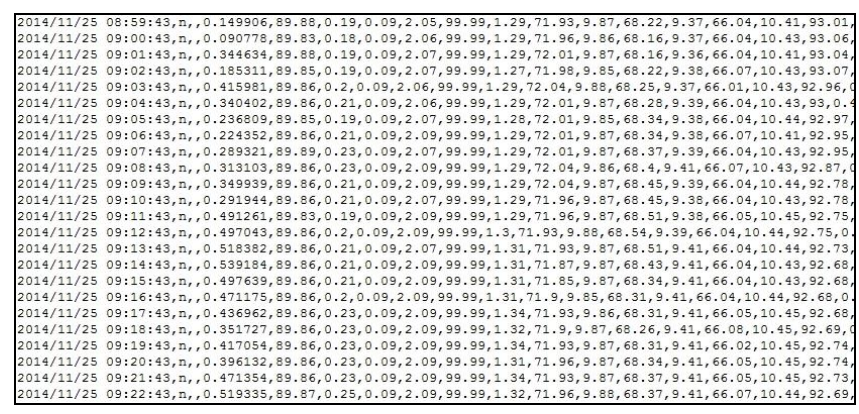

Fig. 6. DAS FTP stored data screenshot. 


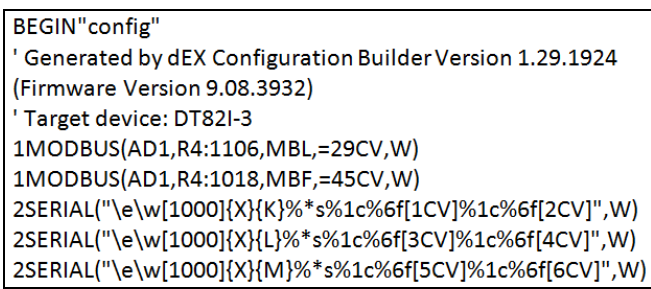

Fig. 7. The digital sensor data acquisition program.

RB"LOGGING"(,,b:",ALARMS:OV:100KB:W60,DATA:OV:80MB)1M
LOGONB
2V(,LOG-Q-WALL W/m2",=36CV,W,40,NA)
1*L(N,"LOG-SOL-AIR.ROOM W/m2",LM,S1,NA,100)
1L(N,"LOG-P.DIF-AIR.ROOM/A Pa",LM,S2,NA,100)

Fig. 8. The analog sensor data acquisition program.

1CV("MET-W.DIR-AIR.OUT: Degrees",FF0)
2CV("MET-W.VEL-AIR.OUT: mm/s",FF2)
3CV("MET-P-AIR.OUT: mBar",FF1)
4CV("MET-H-AIR.OUT.: \%",FF1)
5CV("MET-T-AIR.OUT: DegC",FF1)
6CV("DewPoint: DegC",FF1)

Fig. 9.The weather station sensor data acquisition program

The interface module consists of two connected configurable interface devices [2] in order to provide the required input number for the sensors.

The temperature and humidity measurements of DAS are performed using Sensirion SHT75 smart sensors [14]. The sensor integrates a sensor element, plus signals processing in a compact format, and provides a fully calibrated digital output. A capacitive sensor element is used to measure relative humidity while temperature is measured by means of a band gap sensor. Measurements of differential air pressure are performed using Sensirion SDP1000-L05 low range differential pressure sensor [15]. Solar radiation is measured by Hukseflux LP02 pyranometer [16], which is mounted in the center of window glass. It measures a solar radiation received by a plane surface from a 180-degree field of view angle. The air flow speed is monitored by hotwire anemometer Delta OHM HD103T [17]. The measurements of heat flux density on the surface of the outer wall are performed using 150-S sensor. It is a thermopile sensor which generates an electric voltage proportionally to the $\Delta T$ across the thermocouple hot and cold junctions.

For measuring outdoor environmental parameters weather station Metpak Pro [19] was selected. It is a compact and lightweight multi-sensor instrument that measures the most essential weather parameters. It measures barometric pressure, wind speed and direction, air temperature, humidity, and calculates a dew point using built-in industry standard probe housed in a naturally aspirated radiation shield.

For measuring of electric parameters the three phase electric power meter/analyzer with Modbus serial interface ABB A43 was used [18].

In order to perform precise simulations and calculations in low energy consumption buildings it is very important to take into account the generated energy from all heat sources. The heat balance in the test stands is characterized by the equation [6]:

$$
\Phi_{L}+\Phi_{S}=\Phi_{G}+\Phi_{H V A C},
$$

where $\Phi_{L}$ is heat loss, $\Phi_{S}$ is accumulated heat, $\Phi_{G}$ is heat gain, $\Phi_{\text {HVAC }}$ is auxiliary heat from heating or cooling units.

In drawing up the heat balance, not only HVAC system radiated heat energy for maintaining the indoor microclimate must be taken into account, but also the heat energy radiated by other electrical equipment and occupants:

$$
\Phi_{G}=Q_{E E}+Q_{E L}+Q_{O}+Q_{S},
$$

where $Q_{E E}$ is heat generated by the electric equipment, $Q_{E L}$ is heat generated by electric light equipment, $Q_{o}$ is occupants' generated heat, $Q_{S}$ is solar radiation heat through a window.

To achieve that, consumed energy metering must be separated for HVAC system and for other power consumers. For this purpose in the test stand energy metering is performed in the separate power phases. That is provided by the threephase electric energy meter, which is connected to the data logger using serial interface.

The data logger is receiving information about all three power phases L1, L2 and L3, including total power consumption, an instantaneous power, a current and a voltage. Power consumption in phases is grouped into three categories: L1 - a heat pump, L2 - an electric convection heater, L3 additional electric equipment (data logger, measuring equipment, electric light units, etc.).

The data acquisition from all sensors is performed by the developed data logger DT82i program. It is made by sending queries to the sensors. There are two parts in the program. One is used for the digital sensors including temperature, humidity, and pressure sensors. The screenshot of the developed DT82 $\mathrm{i}$ program's fragment, shown in Fig. 7, is containing the queries to the digital sensors. Another is used for the sensors with analog signal output (Fig. 8).

The data acquisition from weather station sensors is performed by the program shown in Fig. 9.

\section{MEASUREMENTS AND RESULTS}

Each data logger is reading data from analog and digital channels. Measurements can be displayed directly on a screen using WEB access (Fig. 10) or using data from FTP server. Using accessed data it is possible to create all necessary data graphics.

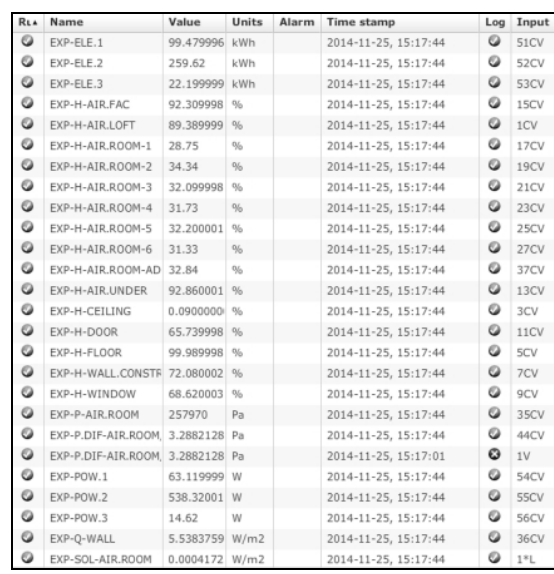

Fig. 10. Real time data screenshot of data logger web interface. 
As an example of measurements data, measured for 24 hours on 06/04/2014, are used. The outdoor air temperature measured by the weather station (MET) and the test stand (LOG) indoor air temperature and humidity changes schedules are shown in Fig. 11. The HVAC system installed in the test stand is switched on the air ventilation mode. The heating and cooling of the test stand is switched off. The weather station measurements of outdoor wind velocity are shown in Fig. 12.

The weather station measured changes of solar radiation are shown in Fig. 13.

Relation of the outdoor temperature and temperature changes in different indoor places is shown in Fig. 14.

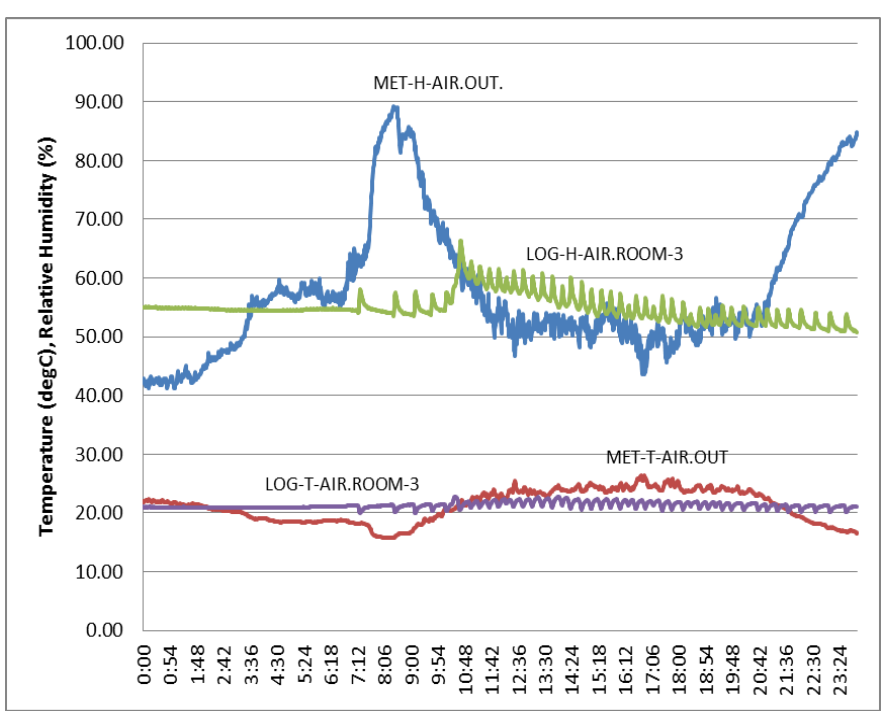

Fig. 11. Indoor and outdoor temperature and humidity changes.

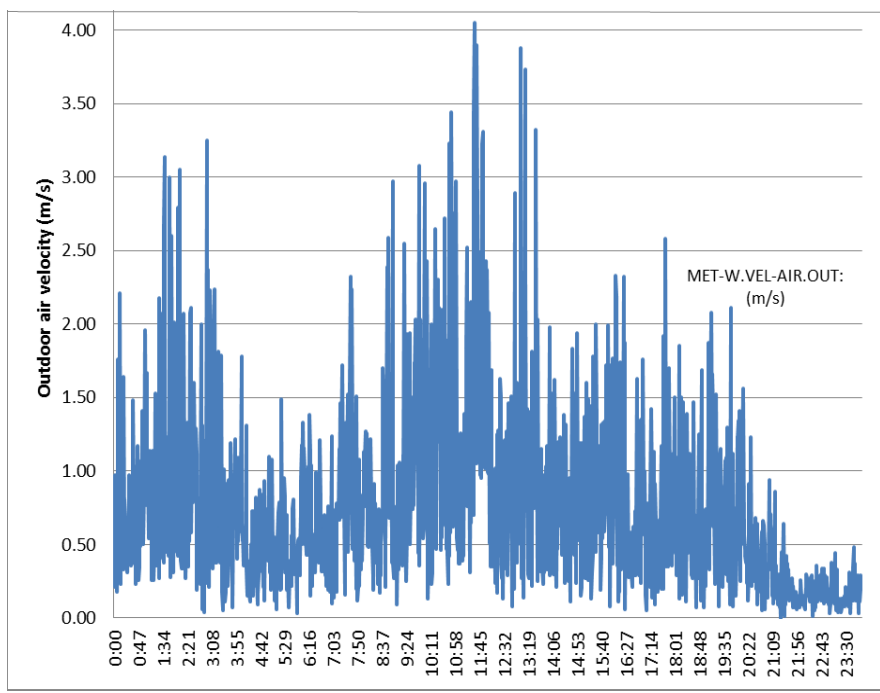

Fig. 12. Changes of outdoor wind velocity.

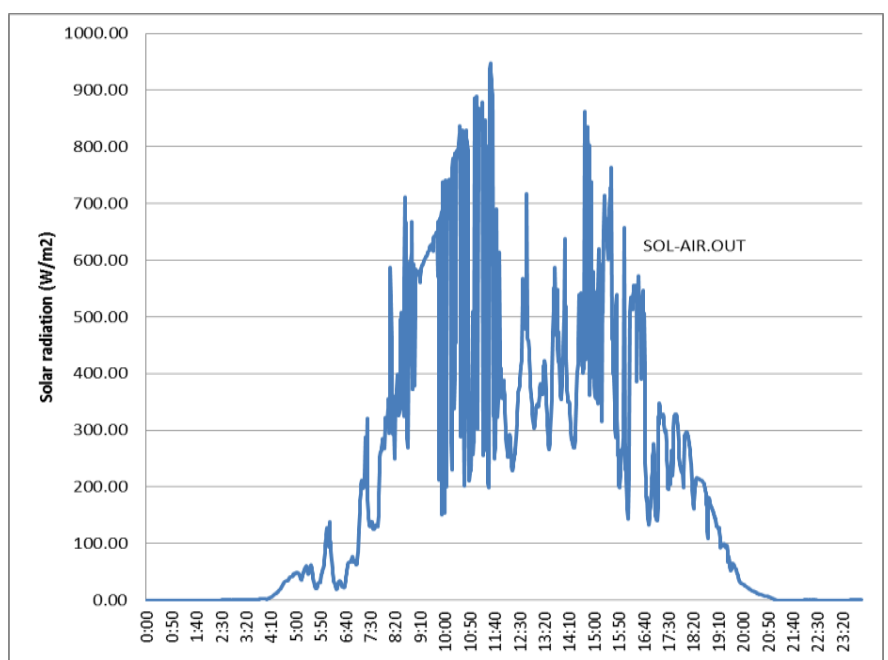

Fig. 13. Changes of solar radiation.

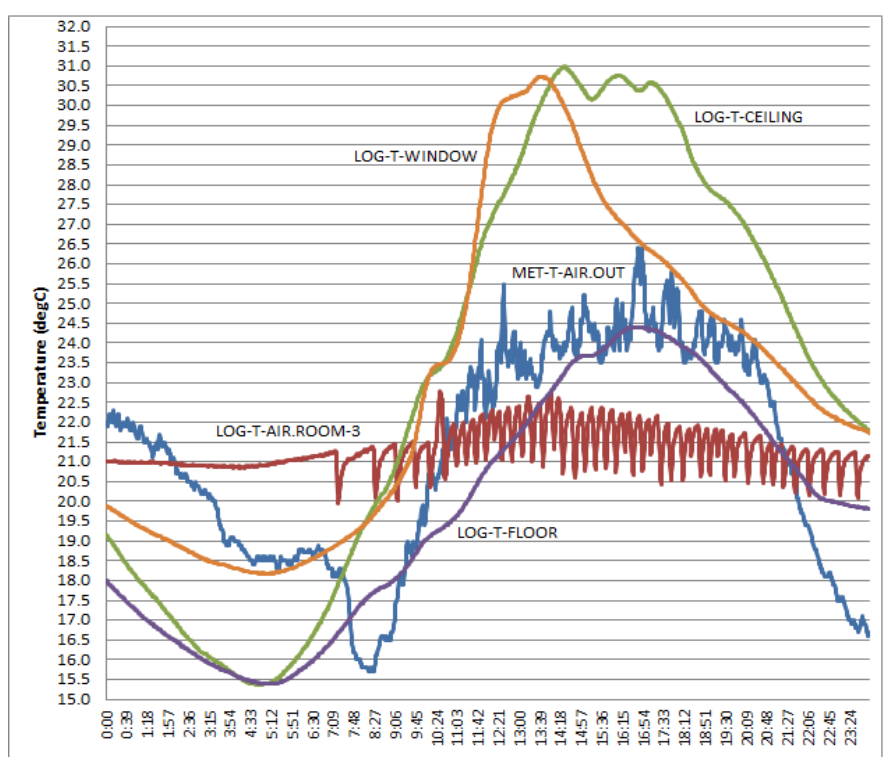

Fig. 14. Temperature of indoor locations.

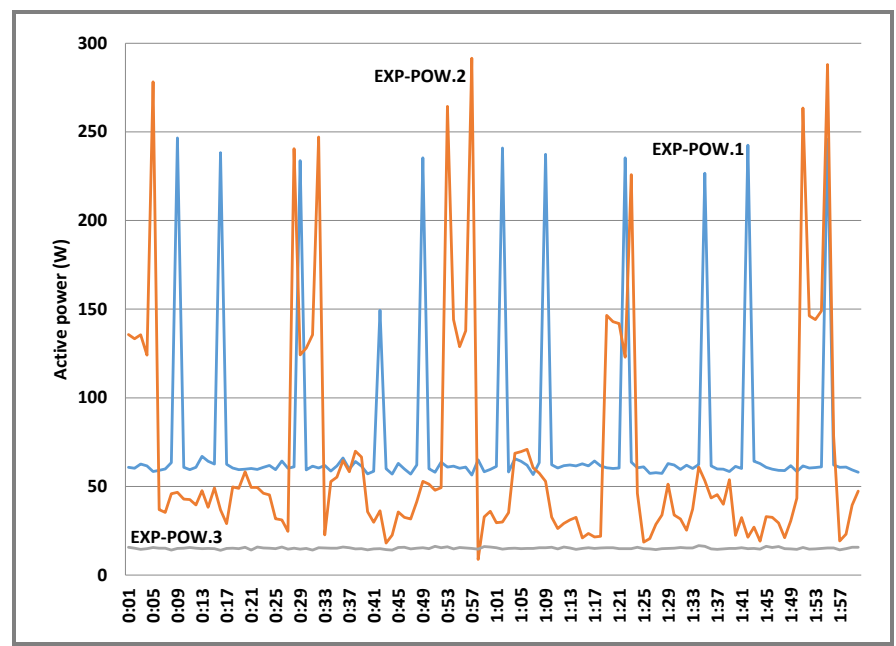

Fig. 15. Active power of the separate phases. 
In Fig. 15 EXP test stand active power measurements in all three phases, done on 12/30/2014, are shown. Power consumption in phases: L1 - ventilation, L2 - an electric heater, L3 - additional equipment.

\section{CONCLUSION}

The selected system architecture is considered to be correct and complies with the energy efficiency monitoring project requirements for the data acquisition system. It provides all the necessary data for environmental parameter monitoring, as well as a remote access for the researchers to the collected data and the remote system administration. Web interface, built in the data logger, is providing access to all measured data parameters in numerical and graphical form. Built-in FTP server and Internet services provide access to many users that essentially increase the speed of information dissemination.

Split electric energy metering allows evaluation of energy efficiency of the test stand HVAC system, taking into account all electrical powered heat energy sources placed in each of test stands.

\section{ACKNOWLEDGEMENT}

This work has been supported by funding from European Social Fund within the grant Nr: 2013/0027/1DP/1.1.1.2.0/13/APIA/VIAA/007.

\section{REFERENCES}

[1] M. Greitans, U. Grunde, A. Jakovics and S. Gendelis, "Web-Based RealTime Data Acquisition System as Tool for Energy Efficiency Monitoring," In Proc. of the Telecommun. forum, TELFOR, 2013, pp. 553-556. http://dx.doi.org/10.1109/TELFOR.2013.6716289

[2] U. Grunde, "Embedded Configurable Sensor Interface Devices for Seamless Data Acquisition," In Proc. of the Telecommun. forum, TELFOR, 2013, pp. 526-528. http://dx.doi.org/10.1109/TELFOR.2013.6716282

[3] V. A. Nagin, I. V. Potapov and S. V. Selishchev, "A distributed component-oriented architecture for real-time ECG data acquisition systems. Engineering in Medicine and Biology Society," In Proc. of the 23rd Annu. Int. Conf. of the IEEE, vol. 4, 2001, pp. 3413-3415. http://dx.doi.org/10.1109/IEMBS.2001.1019562

[4] A. Kuusik, E. Reilent, I. Loobas and A. Luberg, "Data Acquisition Software Architecture for Patient Monitoring Devices," Electronics and Electrical Engineering, vol. 105, no. 9, Kaunas, 2010.

[5] C. C. Robson, S. Silverstein, and A. C. Bohm, "An Operation-Server Based Data Acquisition System Architecture," 15th IEEE-NPSS RealTime Conference, Apr. 29 - May 4, 2007, pp.1-3. http://dx.doi.org/10.1109/RTC.2007.4382788

[6] M.de Wit, Heat Air Moisture Model for Building and Systems Evaluation. Eindhoven: Eindhoven University Press, 2006.

[7] C. De Capua, A. Meduri, and R. Morello, "A smart ECG measurement system based on web-service-oriented architecture for telemedicine applications," IEEE Trans. Instrum. Meas., vol. 99, pp. 1-9, Oct. 2010. http://dx.doi.org/10.1109/TIM.2010.2057652

[8] K. Kalaitzakis, E. Koutroulis and V. Vlachos, "Development of a Data Acquisition System for Remote Monitoring of renewable Energy Systems", vol. 34, 2007. http://dx.doi.org/10.1016/S0263-2241(03)00025-3

[9] R. Khasgiwale, L. Krnan, A. Perinkulam and R. Tessier, "Reconfigurable data acquisition system for weather radar applications," In Proc. of 48th Midwest Symp. on Circuits and Systems, MWSCAS '05, Cincinnati, Ohio, USA, Aug. 2005. http://dx.doi.org/10.1109/MWSCAS.2005.1594227

[10] M. Q. Leite, L. H. Najm, P. L. P. Correa, A. V. Neto, and V. L. I. Fonseca, "System architecture for data acquisition, extraction and analysis for experiments with weblabs," In 2010 Fifth International Conference Digital Information Management, ICDIM, July 2010, pp.56-62. http://dx.doi.org/10.1109/ICDIM.2010.5664621

[11] R. Kirubashankar, K. Krishnamurthy, J. Indra and B. Vignesh, "Design and Implementation of Web Based Remote Supervisory Control and
Information System," International Journal of Soft Computing and Engineering, IJSCE, vol. 4, no. 1, Sept. 2011.

[12] Energy efficiency monitoring project homepage. [Online]. Available: http://www.eem.lv

[13] DataTaker, DT80/81/82/85, Series 1, 2 \& 3, User's Manual. 2011. [Online]. Available: http://www.datataker.com/documents/manuals/UM0085-B7/20-/20DT8x/20Users/20Manual.pdf

[14] Sensirion. The Sensor Company, Datasheet SHT7x Humidity and Temperature Sensor IC. [Online]. Available: http://www.sensirion.com/ fileadmin/user_upload/customers/sensirion/Dokumente/Humidity/Sensir ion_Humidity_SHT7x_Datasheet_V5.pdf

[15] Sensirion. The Sensor Company, SDP1000 / SDP2000 Low Range Differential Pressure Sensor for Air and Non-Aggressive Gases, Datasheet. [Online]. Available:

http://www.sensirion.com/fileadmin/user_upload/customers/sensirion/D okumente/DiffPressure/Sensirion_Differential_Pressure_SDP1000_SDP 2000_Datasheet_V5.pdf

[16] Hukseflux. Thermal Sensors, LP02 pyranometer, Datasheet. [Online]. Available: http://www.hukseflux.com/product/lp02-pyranometer

[17] HD103T.0 Active Air speed transmitter, Datasheet. [Online]. Available: http://www.deltaohm.com/ver2008/uk/depliant/hd103T_D_uk.pdf

[18] ABB, A43/A44 User manual. [Online]. Available: http://www05.abb.com/global/scot/scot349.nsf/veritydisplay/3e5ebfc4ba 5091aec12579b90026bb5f/\$file/2cmc484001m0201_a_en_a43_a44_use r_manual.pdf

[19] MetPak PRO, User manual, Gill instruments. [Online]. Available: http://gillinstruments.com/data/manuals/1723-ps-0015-metpak-pro-usermanual-issue-2.pdf

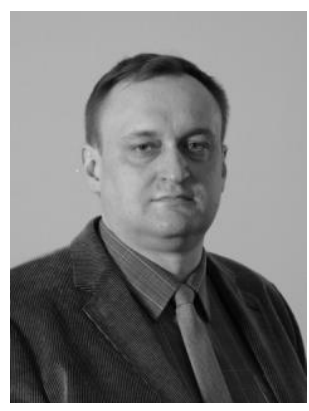

Ivars Beinarts received Dr. sc. ing. in 2011 and has been a researcher since 2009. His major field of study is computer control of electrical technologies.

Currently he is a Senior Researcher with the Institute of Industrial Electronics and Electrical Engineering of Riga Technical University.

His main research interests are related to automatic control of electric processes and apply of AI methods.

Address: Riga Technical University, 12/1 Azenes Str., Riga, Latvia LV-1048.

E-mail: ivars.beinarts@latnet.lv Phone: +37167200515.

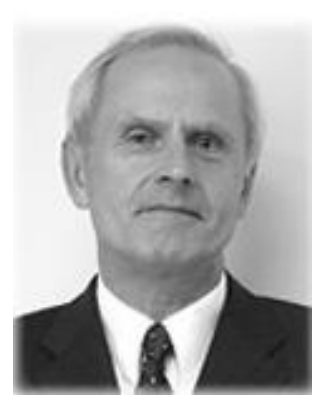

Uldis Grunde graduated from the University of Latvia in 1969, and received Ms. Sc. in Physics. He joined the Institute of Electronics and Computer Science (IECS) in 1969. He has gained experience in research and development of real time control systems.

Since 2006, he has been a researcher with Embedded Systems Laboratory at IECS, Riga, Latvia. Currently he is involved in research of non-conventional methods of signal processing and their applications in processing of nonstationary signals. He is a member of IEEE and ACM.

Address: Institute of Electronics and Computer Science, 14 Dzerbenes Str., Riga, Latvia LV-1006.

E-mail: uldis.grunde@edi.lv

Phone: +37167558130

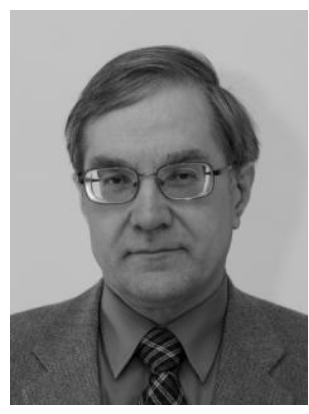

Andris Jakovics received Dr. Phys. in 1979 and since 2002 has been Assoc. Professor with the University of Latvia, Currently he is Head of the Chair of Electrodynamics and Continuum Mechanics at the University of Latvia.

His main research interests are related to numerical and experimental investigations of heat and mass transfer processes in several technical applications.

Postal address: University of Latvia, 8 Zellu Str., Riga, Latvia LV-1002.

E-mail: andris.jakovics@lu.lv

Phone: +37129155711 